\title{
Rentabilidade da produção familiar de laranja Valência: estudo de caso no município de Mogi Guaçu - SP
}

\author{
Elaine Cristina Leonello ${ }^{1}$, Maura Seiko Tsutsui Esperancini ${ }^{2} \&$ Saulo Phelipe Sebastião Guerra ${ }^{2}$
}

\section{RESUMO}

Na última década a citricultura brasileira vem enfrentando grandes desafios com a queda tendencial da demanda dos principais mercados consumidores de suco de laranja. Além disso, a produção citrícola tem enfrentado uma conjunção de fatores nem sempre favoráveis à produção, como quedas de preços e aumento de custos, principalmente devido ao ataque de pragas e doenças. No setor há basicamente dois mercados consumidores distintos: consumo in natura (laranja de mesa) e matéria-prima para produção de suco e produtos secundários oriundos de laranja (laranja de indústria). Grandes produtores de laranja baseiam a rentabilidade de seu sistema na especialização da produção de laranja para indústria, pois permite maior eficiência do trabalho e no uso de bens de capital. No entanto, pequenos citricultores têm mais facilidade em administrar e combinar diferentes manejos para a produção de laranja para mesa e para indústria concomitantemente, possibilitando reduzir risco de preços desfavoráveis em um determinado mercado. Procurou-se verificar se essa estratégia alcançou o objetivo de gerar lucro na produção de laranja para mesa e para indústria em um ambiente de risco de mercado a partir de um estudo de caso de uma propriedade familiar de 20 hectares com laranja valência na região de Mogi Guaçu/SP. Os resultados mostram que, mesmo em pequenas escalas de produção, é possível obter níveis satisfatórios de rentabilidade, com indicadores assumindo valores positivos e satisfatórios.

Termos de indexação: agricultura familiar, citricultura, laranja de mesa, laranja de indústria.

\section{Profitability of Valencia orange production in a family farm: a case study in the municipality of Mogi Guaçu, Sao Paulo State, Brazil}

\section{SUMMARY}

In the last decade, the Brazilian citriculture has been facing great challenges with the tendential fall of the main consuming markets of orange juice demand. Furthermore, citrus production has faced a combination of factors not always favorable to production such as price declines and rising costs, mainly due to the attack of pests and diseases. In the sector, basically there are two distinct consumer markets: consumption in natura and raw material for juice production and industrialized by-products from orange. Orange large producers base their system's profitability on the specialization

\footnotetext{
${ }^{1}$ Programa de Pós-graduação em Energia na Agricultura, Faculdade de Ciências Agronômicas, Universidade Estadual Paulista "Júlio de Mesquita Filho" - UNESP, Botucatu, SP, Brasil

2 Departamento de Economia, Sociologia e Tecnologia, Faculdade de Ciências Agronômicas, Universidade Estadual Paulista

"Júlio de Mesquita Filho" - UNESP, Botucatu, SP, Brasil

Autor correspondente: Maura Seiko Tsutsui Esperancini, Departamento de Economia Sociologia e Tecnologia, Faculdade de Ciências Agronômicas, Universidade Estadual Paulista - FCA/UNESP, Av. Universitária, 3780, CEP 18610-034, Botucatu, SP, Brasil. Email: maura@fca.unesp.br
} 
of orange production for industry as it allows greater labor efficiency and greater use of capital goods. However small citrus growers are more likely to rule and combine different managements for the production of orange in natura and for industry concurrently, making it possible to reduce risk of unfavorable prices in a given market. We aim to verify if this strategy reaches the objective of generating profit in the production of orange in natura and orange for industry in a market risk environment based on a case of a 20-hectare family property with Valência orange in the region of Mogi Guaçu/SP. The results show that even at small production scales it is possible to obtain satisfactory

levels of profitability, with indicators assuming positive and satisfactory values.

Index terms: Family farm, citriculture, orange in natura, orange for industry.

A despeito da importância da citricultura brasileira no mundo não só em termos de produção de laranja (34\% do total) e de sucos concentrados e congelados ( $56 \%$ do total), na última década o setor vem enfrentando grandes desafios. O setor citrícola brasileiro destina 97\% de sua produção para o mercado externo na forma de suco concentrado e congelado e apenas $3 \%$ da produção ao mercado doméstico (Neves \& Trombin, 2017).

Um dos principais desafios para o segmento citrícola é a queda da demanda nos principais mercados consumidores de suco de laranja. Nos últimos 10 anos o consumo mundial caiu 500 mil toneladas passando de 2,3 milhões de toneladas em 2007 para 1,8 milhões de toneladas em 2017, enquanto o consumo da fruta in natura permaneceu relativamente estável no período. Como reflexo, as exportações, principal destino da produção brasileira, também apresentaram retração nesta última década, passando de 1,28 milhões de toneladas métricas para 880 mil toneladas métricas. Mesmo o aumento das exportações do NFC (suco integral não concentrado) não foi capaz de compensar a queda expressiva das exportações de suco concentrado e congelado (Barros, 2016).

Além da questão mais estrutural de queda da demanda, a produção citrícola tem enfrentado uma conjunção de fatores nem sempre favoráveis às melhores condições de rentabilidade, tais como quedas de preços e aumento de custos, principalmente mão de obra e ataque de pragas e doenças em pomares comerciais, como o huanglongbing (HLB ou greening) e a pinta-preta (Pagliuca et al., 2012; Erpen et al., 2018).

No setor citrícola há basicamente dois mercados consumidores distintos: laranja produzida para consumo in natura (laranja de mesa) e como matéria-prima industrial para produção de suco e produtos secundários (laranja de indústria). O destino final da produção influencia os indicadores de rentabilidade, pois para cada consumo específico existem restrições e/ou demandas de uso de determinados produtos químicos durante o manejo.
Por exemplo, para o consumo in natura, é importante o maior cuidado com o aspecto visual da fruta, sendo aprazível que não haja sintomas de pinta preta na fruta, o que exige avaliação continuada e controle com fungicidas; em contrapartida, o consumo industrial apresenta exigências quanto ao teor de açúcares, além da restrição do uso de fungicidas com ingrediente ativo carbendazim. Se, de um lado o custo de produção da laranja de mesa é maior, o produto é comercializado a preços maiores, enquanto a laranja para indústria pode ser produzida a um menor custo e, geralmente é vendida a um menor preço (Erpen et al., 2018).

Produtores de laranja em grandes áreas baseiam a rentabilidade do sistema produtivo na produção de laranja para indústria em razão da especialização em grandes áreas, pois permite maior eficiência no uso de bens de capital, ao investir uma quantidade moderada de capital por unidade de área, o que ocorre com maquinaria de maior porte, por exemplo. Também áreas maiores permitem a maior eficiência do trabalho pois permite o desenvolvimento de habilidades ao efetuar determinados serviços.

Pequenos citricultores, por outro lado, têm mais facilidade em combinar diferentes manejos do sistema produtivo para a produção de laranja de mesa e de indústria, possibilitando reduzir o risco de preços desfavoráveis em um determinado mercado.

De acordo com Clemente et al. (2015), no estado de São Paulo, $48 \%$ do total das propriedades citrícolas são menores que 100 hectares e apenas $17 \%$ delas sãos maiores que 300 hectares. Dessa forma, a sobrevivência de pequenas e médias propriedades citrícolas depende de estratégias que maximizem a rentabilidade, em um ambiente de extrema variabilidade de mercado e de risco climáticos e biológicos, pois estas são mais sensíveis financeiramente às variações de mercado.

Uma das estratégias para obtenção de lucro para alguns pequenos citricultores é a flexibilização do manejo do sistema de tal forma a atender ao mercado de laranja de mesa e laranja de indústria. Neste estudo procurou-se verificar se tal estratégia atingiu o objetivo de gerar lucro na produção de laranja para mesa e para indústria em um ambiente de risco de mercado, a partir de um estudo de 
caso de um produtor familiar da região de Mogi Guaçu, na divisão da região mais produtiva de laranja do país (estado de São Paulo e região do Triângulo Mineiro), com 20 hectares com laranja Valência em porta-enxerto limoeiro "Cravo".

A cultura foi implantada no ano de 2004, com espaçamento de $6,0 \mathrm{~m} \times 3,0 \mathrm{~m}$, totalizando 556 plantas por hectare, cujo manejo visava a produção de laranja para mesa. No $3^{\circ}$ ano, o pomar iniciou sua produção com 188 caixas por hectare que foram direcionados para a indústria por apresentar características de tamanho pouco aceitas pelo mercado da laranja de mesa. A partir do $5^{\circ}$ ano foi possível, a partir dos ajustes no sistema de produção, direcionar parte da produção ao mercado de laranja de mesa.

Os registros do produtor mostram que as operações mecanizadas para a implantação da cultura foram gradagem, subsolagem, adubação de base e preparo de covas para a plantio e irrigação e o plantio de mudas feito manualmente.

Na fase de manutenção da cultura as principais operações mecanizadas foram a adubação de cobertura (três vezes ao ano), a capina química na linha (uma vez ao ano), a roçada mecanizada (uma vez ao ano) e a aplicação de inseticidas (36 vezes ao ano), acaricidas (uma vez ao ano), fungicidas e bactericidas (6 vezes ao ano). Manualmente foram feitas, em geral, as seguintes operações: replantio, controle de formiga (duas vezes ano), desbrota manual (três vezes ao ano). Os equipamentos disponíveis para a implantação e manutenção da cultura são trator $75 \mathrm{hp}$, grade aradora 16 discos de 26", escarificador de arraste com três lâminas, adubador pendular de $600 \mathrm{~kg}$, grade niveladora 32 discos de 20", pulverizador subatomizador de 2.000 litros, barra aplicadora de 600 litros, roçadeira e carreta de duas toneladas.

A região macroprodutora tem a presença do huanglongbing (HBL, causado pelo patógeno Candidatus Liberibacter spp.), e o controle do psilídeo vetor é intensamente feito a partir das pulverizações com inseticidas executadas a cada decêndio. Fukuda et al. (2010) indicam que os custos decorrentes desse manejo intensivo por consequência da doença aumentam significativamente, mas também indicam que tecnologias e melhores práticas vêm sendo desenvolvidas para aumento da produtividade dos pomares, o que, segundo os autores, é a opção mais palpável para resolução desta questão. Uma outra opção, menos racionalmente competitiva, seria aumentar o preço do produto visando o aumento da renda bruta.

Os insumos mais utilizados foram fertilizante 20-00-20 (composto químico formulado com $20 \%$ de N, sem a presença de $\mathrm{P}_{2} \mathrm{O}_{5}$ e $20 \%$ de $\mathrm{K}_{2} \mathrm{O}$ ), herbicida gliphosate, formicida a base de sulfluramida, inseticida (piretroide, organofosforado, neonicotinoide), acaricidas diversos, fungicidas diversos e espalhante adesivo.

Tabela 1. Preços de venda e produção de laranja de mesa e laranja de indústria, de 2004 a 2017

\begin{tabular}{|c|c|c|c|c|}
\hline \multirow{3}{*}{ Ano } & \multicolumn{2}{|c|}{ Preço de Venda } & \multicolumn{2}{|c|}{ Produção } \\
\hline & Laranja de Mesa & Laranja Indústria & Laranja de Mesa & Laranja Indústria \\
\hline & \multicolumn{2}{|c|}{$\left(\mathrm{R} \$ \text { caixa }^{-1}\right)^{*}$} & \multicolumn{2}{|c|}{$\left(\right.$ caixa ha $\left.^{-1}\right)$} \\
\hline 2004 & - & - & - & - \\
\hline 2005 & 6,50 & 5,50 & 0 & 0 \\
\hline 2006 & 10,50 & 10,50 & 0 & 0 \\
\hline 2007 & 12,00 & 12,00 & 0 & 183 \\
\hline 2008 & 15,00 & 14,50 & 0 & 556 \\
\hline 2009 & 10,50 & 9,50 & 250 & 583 \\
\hline 2010 & 6,50 & 5,00 & 417 & 972 \\
\hline 2011 & 5,50 & 5,50 & 417 & 972 \\
\hline 2012 & 8,00 & 10,50 & 833 & 833 \\
\hline 2013 & 8,00 & 7,00 & 833 & 833 \\
\hline 2014 & 9,00 & 7,50 & 1000 & 667 \\
\hline 2015 & 20,50 & 18,00 & 1361 & 583 \\
\hline 2016 & 24,00 & 20,00 & 1556 & 389 \\
\hline 2017 & 24,00 & 22,00 & 1250 & 417 \\
\hline
\end{tabular}

*Caixa com 40,8 kg de laranja.

Fonte: Elaborado pelos autores (2018). 
Também foram coletados os preços recebidos pelo produtor da laranja de mesa e da laranja de indústria, bem como a produção anual (Tabela 1).

A partir da matriz de coeficientes técnicos e dos preços dos insumos foram estimados os custos operacionais do ano de 2004 ao ano de 2017. Aos custos operacionais foram acrescidos demais encargos para a obtenção do custo operacional total (COT).

A produção destinada à indústria gera despesa de colheita, uma vez que a comercialização tradicional é realizada "posto fábrica", portanto os valores dispendidos com colheita e transporte são de responsabilidade do produtor. A laranja destinada à mesa é comercializada "no pomar", portanto os custos de colheita e transporte são de responsabilidade do comprador.

As receitas foram obtidas a partir das quantidades produzidas de laranja para mesa e para indústria e seus respectivos preços. Os dados foram atualizados para o ano de 2017 para permitir a comparação de receitas e os custos, a partir de uma taxa de desconto de $7 \%$ ao ano (Tabela 2).

Para avaliar o desempenho econômico e a lucratividade do sistema de produção foram estimados os seguintes

Tabela 2. Receitas e custos da produção de laranja atualizadas para o ano de 2017, em $\mathrm{R} \$ \mathrm{ha}^{-1}$

\begin{tabular}{crrr}
\hline Ano & $\begin{array}{c}\text { Receita } \\
\text { atualizada }\end{array}$ & & $\begin{array}{c}\text { Custo } \\
\text { operacional total } \\
\text { atualizado }\end{array}$ \\
\cline { 2 - 2 } 2004 & 0,00 & & $\begin{array}{c}12.167,66 \\
\left(\mathrm{R} \mathrm{h} \mathrm{ha-1}^{-1}\right)\end{array}$ \\
2005 & 0,00 & & $6.655,99$ \\
2006 & 0,00 & & $6.514,21$ \\
2007 & $4.327,73$ & & $8.926,70$ \\
2008 & $14.809,81$ & & $23.352,54$ \\
2009 & $14.031,85$ & & $23.211,49$ \\
2010 & $12.154,87$ & & $16.105,53$ \\
2011 & $11.463,91$ & & $17.915,17$ \\
2012 & $21.622,67$ & & $17.276,23$ \\
2013 & $16.384,95$ & & $15.165,82$ \\
2014 & $17.150,60$ & & $12.526,98$ \\
2015 & $43.967,34$ & & $12.358,53$ \\
2016 & $48.268,89$ & & $10.824,83$ \\
2017 & $39.166,67$ & & $10.536,00$ \\
MÉDIA ANUAL & $18.719,18$ & $14.887,51$ \\
\hline
\end{tabular}

Fonte: Elaborado pelos autores (2018). indicadores: margem bruta, renda líquida e índice de lucratividade (Martin et al., 1998).

A margem bruta (MB) é o excedente após o produtor pagar o custo operacional total, considerando determinado preço unitário de venda e o rendimento do sistema de produção para a atividade que compõe a receita bruta da laranja de mesa $\left(\mathrm{RB}_{\mathrm{LM}}\right)$ e receita bruta da laranja de indústria $\left(\mathrm{RB}_{\mathrm{LI}}\right)$, como mostra a equação (1).

$\mathrm{MB}(\mathrm{COT})=\frac{\mathrm{RB}_{\mathrm{LM}}+\mathrm{RB}_{\mathrm{LI}}-\mathrm{COT}}{\mathrm{COT}} \times 100$

O lucro operacional (LO) mostra o ganho por unidade de área, uma vez cobertos os custos operacionais totais. É dado pela Receita Bruta da laranja de mesa $\left(\mathrm{RB}_{\mathrm{LM}}\right)$ e da laranja de indústria $\left(\mathrm{RB}_{\mathrm{LI}}\right)$ menos o custo operacional total (COT), conforme equação 2.

$\mathrm{LO}=\left(\mathrm{RB}_{\mathrm{LM}}+\mathrm{RB}_{\mathrm{LI}}\right)-\mathrm{COT}$

O índice de lucratividade mostra a relação entre o lucro operacional (LO) e a receita bruta da laranja de mesa $\left(\mathrm{RB}_{\mathrm{LM}}\right)$ e receita bruta da laranja de indústria $\left(\mathrm{RB}_{\mathrm{LI}}\right)$, em percentagem. É uma medida importante de rentabilidade da atividade agropecuária, uma vez que mostra a taxa disponível de receita da atividade, após o pagamento de todos os custos operacionais, encargos e depreciações, conforme mostra a equação 3 .

$\mathrm{IL}=\frac{\mathrm{LO}}{\mathrm{RB}_{\mathrm{LM}}+\mathrm{RB}_{\mathrm{LI}}} \times 100$

Os resultados mostram que mesmo em pequenas escalas de produção é possível obter bons níveis de rentabilidade, na média da vida útil de um pomar. Foram obtidos os valores de $25,7 \%$ na margem bruta, $\mathrm{R} \$ 3.831,7$ ha ano ${ }^{-1}$ no lucro operacional e 20,5\% no índice de lucratividade. Os valores indicam rentabilidade satisfatória da produção.

Carrer \& Souza Filho (2016) reportam que há propriedades com baixa escala de produção operando com alta eficiência de custo. Em contrapartida, Gameiro et al. (2011) reportam que grandes propriedades citrícolas especificamente especializadas nas etapas de manejo e colheita apresentam custos muito inferiores, melhorando os resultados econômicos da cultura, ocorrência notória em grandes propriedades que destinam sua produção para o processamento industrial.

Frente aos resultados obtidos, identifica-se que o pequeno empreendimento ou pequena propriedade agrícola com cultivo de laranja pode ser rentável do ponto de vista econômico. A rentabilidade ou a eficiência do plantio deve estar atrelada a conhecimento técnico e de boas práticas de manejo, buscando sempre a otimização dos recursos, seja pela economia das despesas, seja pela utilização 
racional e sustentável de produtos que promovam renda superavitária em relação aos custos.

\section{REFERÊNCIAS}

Barros, G. S. C. (2016). Medindo o crescimento do agronegócio: bonança externa e preços relativos. In: Vieira Filho, J. E. R., \& Gasques, J. G. (Orgs.), Agricultura, transformação produtiva e sustentabilidade (391 pp.). Brasília: Ipea.

Carrer, M. J., \& Souza Filho, H. M. (2016). Economias de escala e eficiência econômica na produção de laranja no estado de São Paulo. Revista de Economia e Sociologia Rural, 54(1), 51-70.

Clemente, F., Gomes, M. F. M., \& Lírio, V. S. (2015). Análise da eficiência técnica de propriedades citrícolas do Estado de São Paulo. Economia Aplicada, 19(1), 63-79.

Erpen, L., Muniz, F. R., Moraes, T. S., \& Tavano, E. C. R. (2018). Análise do cultivo da laranja no Estado de São Paulo de 2001 a 2015. Revista iPecege, 4(1), 33-43.

Fukuda, L. A., Franco, D., Facio, S. L., \& Lima Neto, R. S. (2010). Sustentabilidade econômica da citricultura perante o huanglongbing. Citrus Research \& Technology, 31(2), 107-114.

Gameiro, A. H., Tizato, L. H. G., \& Caixeta-Filho, J. V. (2011). Economic evalution of loading systems for citrus destined for industrial processing. Citrus Research \& Technology, 32(1), 1-8.

Martin, N. B., Serra, R., Oliveira, M. D. M., Ângelo, J. A., \& Okawa, H. (1998). Sistema integrado de custos agropecuários - Custagri. Informações Econômicas, 28(1), 7-27.

Neves, M. F., \& Trombin, V. G. (2017). Anuário da citricultura 2017 (57 pp.). São Paulo: Citrus BR.

Pagliuca, L., Cappello, F. P., Viana, M., Lorenzi, C., Boteon, M., Borgato, E., \& Lourencini, I. (2012). Sustentabilidade da citricultura é ameaçada pelos altos custos de produção. Hortifruti Brasil, 112, 10-21.

Recebido: Junho 14, 2018 Aceito: março 08, 2019

Como citar: Leonello, E. C., Esperancini, M. S. T., \& Guerra, S. P. S. (2019). Rentabilidade da produção familiar de laranja Valência: estudo de caso no município de Mogi Guaçu - SP. Citrus Research \& Technology, 40, e1043. http://dx.doi.org/10.4322/crt.00160. 